\title{
A selection experiment with pigs: comparison of the effectiveness of individual selection and sib selection
}

\author{
D. MINKEMA ${ }^{1}, M^{2}$ BEKEDAM ${ }^{2}$, D. KROESKE $^{1}$ and TH. STEGENGA ${ }^{2}$ \\ 1 Instituut voor Veeteeltkundig Onderzoek "Schoonoord" Zeist, Netherlands \\ 2 Dept. of Animal Husbandry, Agricultural University, Wageningen, Netherlands
}

\section{Summary}

Two methods of selecting boars for breeding are compared, viz. individual selection and sib selection. To this end one young boar and four full sibs (two barrows and two gilts) were chosen from each of 40 herdbook litters of the Dutch Landrace and fattened individually from 22 to $90 \mathrm{~kg}$ live weight. Backfat thickness and the area of a cross-section of the Musculus longissimus dorsi were measured on the live boars by means of ultra-sonic apparatus. The full sibs of the boars were slaughtered, after which the thickness of their backfat and the percentage of cutlets were determined (instead of the area of the Musc. long. dorsi).

Eight boars were selected for breeding, viz. some of the best and the worst on the basis of their own performance (individual selection) as well as some of the best and the worst on the basis of the performance of their full sibs (sib selection). The selection was carried out by means of an index consisting of the characters food conversion, daily gain, backfat thickness and area of $M$ usc. long. dorsi (or percentage of cutlets).

These boars were used in A.I. and mated with randomly selected groups of sows. Offspring of the boars was afterwards fattened from 22 to $90 \mathrm{~kg}$ live weight and slaughtered. Each progeny test was based on $20-23$ gilts out of the same number of litters.

With the help of the results of the progeny test it was shown that both selection methods had a significant effect. The response with individual selection was 1,9 times greater than that with sib selection, but this difference was not significant.

However, an additional advantage of the individual selection is that it permits a more intense selection than sib selection, since the capacity of the pig-testing stations is limited.

\section{Introduction}

Selection is one of the main tools for improving the genetic make-up of our farm animals. In pig breeding the most important systems of selecting boars are as follows:

a. individual selection $=$ selection on the basis of own performance;

b. sib selection $=$ selection on the basis of the performance of full sibs;

c. progeny testing $=$ selection on the basis of the performance of offspring.

Individual selection means that the future breeding boars are examined in a performance test and cannot, of course, be slaughtered. With the other two selection methods the tested relatives (full sibs or progeny) can be killed at the end of the test period for carcas evaluation.

Received for publication 10th July, 1964. 
Theoretical studies have shown that in pig breeding the individual performance test is the most effective selection method and progeny testing the worst, provided the economically important characters can be determined without slaughtering. If, on the other hand, the characters can only be measured on the slaughtered animals, sib testing or progeny testing has to be applied. In this case sib testing is always more efficient than progeny testing (SMITH, 1959; Kirsch et al., 1962; MinkemA, 1963). The problem can be solved by selection experiments in which the different systems are compared, preferably throughout several generations. However, with large farm animals this is a very time-consuming and expensive business and almost impracticable.

Some years ago MinKEMA and KROESKE (1963) analysed the results of progeny groups of boars. The shortcomings of this selection system are obvious, the main disadvantages of progeny testing being:

a. the low selection intensity owing to the limited capacity of the testing stations;

b. the long generation interval (the boars are at least 18 months old by the time the results of their progeny tests are available).

Until recently a serious drawback of the individual performance test was that no information was supplied about the carcas composition. However, during the last decade methods have been developed for measuring backfat thickness on the live animal, viz. the lean-meter and the ultra-sonic technique (echo-sounding). With echo-sounding the area of cross-sections of the Musculus longissimus dorsi can also be measured, although hitherto rather inaccurately.

It is therefore possible to apply individual selection not only to food conversion, daily gain and body conformation, but also to backfat thickness, and to some extent to the meatiness of the pig. This was the reason for conducting a selection experiment in which the effectiveness of individual selection and sib testing could be compared.

\section{Experimental procedure}

One young boar and four full sibs ( 2 barrows and 2 gilts) were selected from each of 40 herdbook litters of the Dutch Landrace. These litters were born within a limited period, viz. between October 13th and December 1st, 1960. The forty boars were reared in individual pens without runs at the experimental station of the Department of Animal Husbandry, Wageningen. Their full sibs were sent to the progeny-testing station at Lochem in accordance with the standard selection procedure in the Netherlands. At this station the pigs were housed and fed individually.

Both boars and litter mates were fed to appetite twice daily on the standard progenytesting ration, the test starting at $22 \mathrm{~kg}$ live weight and finishing at $90 \mathrm{~kg}$ live weight. Food conversion and daily gain during the test period were calculated for each pig. At a live weight of $90 \mathrm{~kg}$ backfat thickness and the area of a cross-section of the Musc. long. dorsi were measured by means of ultra-sonics. Backfat thickness was the average of three measurements, taken at the shoulder, the middle of the back and the loin, in each case $3 \mathrm{cms}$ off the midline of the back. The area of the Musc. long. dorsi (eye-muscle area) was determined just behind the tip of the last rib.

The tested full sibs of the boars were killed at $90 \mathrm{~kg}$ live weight and a number of carcas measurements were taken according to the standard procedure for pigs of the progeny-testing stations. Backfat thickness, determined by a ruler along the mid- 
line of the back, was the average of five measurements, viz. one taken at the shoulder, two at the middle of the back and two at the loin. The area of the eye muscle was not determined and was replaced by the percentage of cutlets (cutlet weight as a percentage of dead weight).

Eight of the 40 boars were selected for breeding, viz. the two best and the two worst on the basis of their own merits, and the two best and two worst on the basis of the merits of their full sibs. The selection was carried out by means of a selection index consisting of the characters food conversion, daily gain, backfat thickness and area of Musc. long. dorsi (or percentage of cutlets).

The 8 boars were placed in A.I. centres and each boar was mated with a large group of sows, taken at random from the population. Afterwards offspring of the boars was collected, fattened from $22-90 \mathrm{~kg}$ live weight and slaughtered. The progeny test of each boar was based on 23 gilts out of the same number of litters.

In this way it was possible to see to what extent the good and poor qualities of the boars or their full sibs were reflected in the progeny of the boars. The relative effectiveness of individual selection and sib selection was therefore tested against the progeny test.

\section{Selection index}

As already mentioned, we selected for four characters simultaneously. It has been shown theoretically that the maximum improvement for economic merit will be made if the selection is based on an index in which the separate characters are combined. For our experiment we constructed a fairly simple selection index. Each character was weighted by the product of its economic value (a) and its heritability $\left(h^{2}\right)$. Genetic correlations between the characters were not taken into consideration owing to the lack of sufficient information.

The economic value of a character is the monetary return obtained by increasing the character by one unit. We tried to estimate these economic values as accurately as possible for Dutch conditions at the moment of selection. In the absence of Dutch data the heritabilities were mainly derived from Danish literature, based on data from progeny-testing stations with individual feeding (FrEDEEN and Jonsson, 1957; Jonsson, 1959). The components required for constructing the selection index are listed in TABLE 1.

The heritabilities of food conversion and daily gain were probably too high; Jonsson (1963) afterwards published figures which were much lower. It is therefore very

Table 1. Components for the construction of the selection index

\begin{tabular}{|c|c|c|c|c|}
\hline Character & Units & $\begin{array}{c}\text { Economic } \\
\text { value a } \\
\text { (in cents) }\end{array}$ & $\begin{array}{l}\text { Heritability } \\
\text { h2 }\end{array}$ & $\begin{array}{l}\text { Weighting } \\
\text { factor } w \\
(=a h 2)\end{array}$ \\
\hline Food conversion $F$ & $\begin{array}{l}\text { Scandinavian feed } \mathrm{u} \text { - } \\
\text { nits } / \mathrm{kg} \text { live-weight gain }\end{array}$ & -2136 & 0,59 & -1260 \\
\hline Daily gain $\mathbf{G}$ & $\mathrm{kg} / \mathrm{day}$ & +3200 & 0,50 & +1600 \\
\hline Backfat thickness $\mathrm{B}$ & $\mathbf{c m}$ & -1600 & 0,55 & -880 \\
\hline Area Musc. long. dorsi $\mathrm{M}$. & square $\mathrm{cm}$ & $+\quad 48$ & 0,60 & $+\quad 28,8$ \\
\hline Percentage of cutlets $\mathrm{C} \ldots$ & $\begin{array}{l}\text { cutlet weight as } \% \text { of } \\
\text { dead weight }\end{array}$ & +94 & 0,60 & +56 \\
\hline
\end{tabular}


likely that these characters were given too much weight in the index, but this does not affect the comparison of the efficiency of both selection methods.

As the heritabilities of the characters are all in the neighbourhood of $0,5-0,6$, the economic values are in fact the factors determining the relative importance of the different characters in the selection index.

The following two indices were constructed:

$$
\begin{aligned}
& \text { index I }=-1260 \mathrm{~F}+1600 \mathrm{G}-880 \mathrm{~B}+28,8 \mathrm{M} \\
& \text { index II }=-1260 \mathrm{~F}+1600 \mathrm{G}-880 \mathrm{~B}+56 \mathrm{C}
\end{aligned}
$$

The first was used for selecting the boars on their own performance and the second for selecting boars on the average performance of their full sibs. The second index only differs from the first one with regard to the last character, but we took care to ensure that the area of the Musc. long. dorsi had almost the same relative importance in index $I$ as the percentage of cutlets in index II.

The indexes were so constructed that the boar with the optimum combination of the four characters had the highest index. For example, the boar with the best own performance had the following records: food conversion 2,906 feed units per $\mathrm{kg}$ live-weight gain; daily gain $0,632 \mathrm{~kg}$; backfat thickness $1,77 \mathrm{~cm}$ and area of Musc. long. dorsi $36,4 \mathrm{~cm}^{2}$. His index was therefore -3160 units. and the index of the boar with the worst performance was -5101 units. The negative sign in the indexes is due to the fact that the absolute values were used in the index instead of the deviations from their averages.

Finally, a general remark should be made with regard to the selection index. The relative importance of a particular character for the index can be assessed by multiplying the weighting factor $w$ by the standard deviation $s$ of that character. These standard deviations are listed in TABLE 2. It turns out that daily gain and area of Musc. long. dorsi (or percentage of cutlets) are about equally important. Backfat thickness is four times and food conversion even six times as important as the characters first mentioned.

TABLE 2. Results of the boars and their full sibs

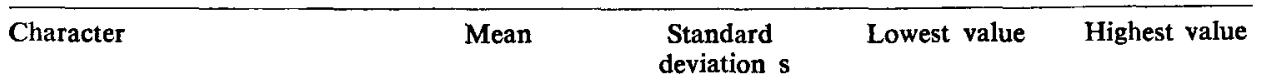

I. Boars at Wageningen (39 a nima Is)

$\begin{array}{lcccc}\text { Selection index I } \ldots \ldots \ldots \ldots & -4152 & 427 & -5101 & -3161 \\ \text { Food conversion } \ldots \ldots \ldots \ldots & 3,27 & 0,235 & 2,91 & 3,87 \\ \text { Daily gain } \ldots \ldots \ldots \ldots \ldots & 0,575 & 0,030 & 0,493 & 0,632 \\ \text { Backfat thickness } \ldots \ldots \ldots \ldots & 2,13 & 0,200 & 1,77 & 2,53 \\ \text { Area } \text { Musc. long. dorsi } \ldots \ldots & 32,0 & 2,72 & 28,2 & 37,5\end{array}$

11. Fullsibs of the Wageningen boarsat Lochem ( 39 test groups)

\begin{tabular}{lcccc} 
Selection index II $\ldots \ldots \ldots \ldots$ & -4659 & 240 & -5104 & -4212 \\
Food conversion $\ldots \ldots \ldots \ldots$ & 3,13 & 0,122 & 2,92 & 3,49 \\
Daily gain $\ldots \ldots \ldots \ldots \ldots$ & $\mathbf{0 , 6 0 8}$ & $\mathbf{0 , 0 2 0}$ & $\mathbf{0 , 5 7 4}$ & 0,643 \\
Backfat thickness $\ldots \ldots \ldots \ldots$ & $\mathbf{3 , 0 0}$ & $\mathbf{0 , 1 5 8}$ & $\mathbf{2 , 6 5}$ & 3,30 \\
Percentage of cutlets $\ldots \ldots$ & 17,00 & 0,631 & 15,90 & 18,07 \\
\hline
\end{tabular}

\section{Results obtained with the boars and their full sibs}

No serious difficulties arose during the experiment and only one out of the 40 boars 
was lost. The mean results obtained with the boars and their full sibs are presented in TABLE 2. Standard deviations and extreme values of the various characters refer to individual values in the case of the boars and to averages of four animals in the case of the full sibs.

The boars showed a worse food conversion and daily gain than their full sibs. This must be due to station differences, the housing conditions at Lochem being better than those at Wageningen. The smaller backfat thickness of the boars resulted from sex differences (boars $v$. barrows and gilts) and different measuring methods. The boars had a better mean selection index than their full sibs; this was primarily caused by thinner backfat of the former.

The standard deviations and ranges are larger for the boars than for their full sibs, because the data for the full sibs are averages of four litter mates.

The relationship between the performance of the boars and the average merit of their full sibs is shown in TABLE 3.

TABLE 3. Correlation between the performance of the boars and the average performance of their full sibs $(n=39)$

\begin{tabular}{|c|c|}
\hline Character & Coefficient of corr \\
\hline  & $\begin{array}{l}+0,35 \\
+0,54 \\
+0,50 \\
+0,07 \\
+0,09\end{array}$ \\
\hline
\end{tabular}

The correlation between the boars and their full-sib averages is fairly good with regard to the selection index and surprisingly good with regard to food conversion and daily gain. The correlation of backfat thickness is lower than was expected. This is probably due to the fact that the backfat of the boars is measured at other places than the backfat of their full sibs. The correlation between area of Musc. long. dorsi of the boars and the percentage of cutlets of their full sibs is also very low, but these two characters are not quite comparable and the ultra-sonic measurement of the Musc. long. dorsi was somewhat inaccurate.

\section{Boars selected for breeding}

The housing and feeding conditions had no detrimental effects on sperm quality and fertility of the boars. Many boars suffered from varying degrees of leg weakness but this proved no drawback for their use in artificial insemination.

As already mentioned, 8 boars were selected out of the 39 that completed the experiment, and were used in A.I. centres in the province of Overijssel. The best boar on the basis of the performance of his full sibs died during transport to the centre and had to be replaced by his reserve. The first crop of offspring could not be collected owing to a heavy outbreak of foot-and-mouth disease, so the boars had to be used again. Meanwhile one of the best boars on own performance, as well as his reserve, had been lost and was replaced by the reserve of the worst boars.

The original experimental design was therefore changed in such a way that the 8 boars used for breeding consisted of one good and three worst ones on the basis of their own merits, and two good ones and two inferior ones on the basis of the merits of their full sibs. These 8 boars are listed in TABLE 4 . 
TABLE 4. Boars selected for breeding

\begin{tabular}{|c|c|c|c|c|c|c|c|c|}
\hline Boar & $\begin{array}{l}\text { Food } \\
\text { conversion }\end{array}$ & $\begin{array}{l}\text { Daily } \\
\text { gain }\end{array}$ & $\begin{array}{l}\text { Backfat } \\
\text { thickness }\end{array}$ & $\begin{array}{l}\text { Area Musc. } \\
\text { long. dorsi }\end{array}$ & Index I & Grade & Rank & $\begin{array}{l}\text { Rank of } \\
\text { full sibs } \\
\text { (index II) }\end{array}$ \\
\hline 1 & 2,906 & 0,632 & 1,77 & 36,4 & -3161 & good & 1 & (8) \\
\hline 2 & 3,615 & 0,541 & 2,30 & 28,8 & -4883 & bad & 37 & (28) \\
\hline 3 & 3,874 & 0,493 & 2,07 & 28,9 & -5082 & bad & 38 & (37) \\
\hline 4 & 3,707 & 0,514 & 2,53 & 33,8 & -5101 & bad & 39 & (30) \\
\hline \multicolumn{9}{|c|}{$\begin{array}{l}\text { Group II. Boars selected on the basis of the performance of their full } \\
\text { sibs }\end{array}$} \\
\hline Boar & $\begin{array}{l}\text { Food } \\
\text { conversion }\end{array}$ & $\begin{array}{l}\text { Daily } \\
\text { gain }\end{array}$ & $\begin{array}{c}\text { Backfat } \\
\text { thickness }\end{array}$ & $\begin{array}{l}\% \text { of } \\
\text { cutlets }\end{array}$ & Index II & Grade & Rank & $\begin{array}{c}\text { Rank of } \\
\text { boar } \\
\text { (index I) }\end{array}$ \\
\hline 5 & 2,922 & 0,632 & 2,87 & 17,35 & -4225 & good & 2 & (13) \\
\hline 6 & 2,967 & 0,630 & 2,87 & 16,97 & -4306 & good & 3 & (7) \\
\hline 7 & 3,210 & 0,592 & 3,30 & 17,27 & -5035 & bad & 38 & (17) \\
\hline 8 & 3,320 & 0,577 & 3,12 & 16,10 & -5104 & bad & 39 & (30) \\
\hline
\end{tabular}

Group I includes the four boars selected on the basis of their own merits (individual selection). The boars' own records for the separate characters and the index are given, together with their grade and the rank assigned to their index. For comparison, the last column shows the ranks assigned to the average index of the litter mates of the boars.

Group II includes the four boars selected on the basis of the performance of their full sibs (sib selection). The results are listed of their full sibs for the separate characters and the index, as well as the rank assigned to this index. The last column shows the ranks attached to the boars on the basis of their own index.

\section{Results obtained with the progeny of the boars}

From each of the 8 boars 23 female decendants were collected within a limited period. The 23 descendants were taken from the same number of litters so as to reduce differences between progeny groups caused by differences in dam quality. Each piglet represented the average quality of its litter. Only gilts were collected so as to avoid sex differences and castration effects.

The $8 \times 23=164$ pigs were fattened from 22 to $90 \mathrm{~kg}$ live weight on the same scheme and ration as pigs from the progeny-testing stations. They were distributed over 4 different stations, 3 with individual feeding and 1 with group-feeding (groups of four pigs). The number of pigs per station varied, but each boar at each station had the same number of progeny.

Some losses occurred, mainly due to an outbreak of foot- and mouth-disease at one of the stations. Finally, the number of progeny slaughtered per boar varied from 20 to 23 pigs. Food conversion, daily gain, backfat thickness, area of Musc. long. dorsi and percentage of cutlets were determined. The last three characters were measured at the carcasses.

There were fairly large differences between the stations, especially with regard to mean food conversion and daily gain, these being caused by differences in environmental conditions. These differences were corrected by expressing the records of each 
pig as deviations from the average results of all pigs at the same station. The weighted mean results of all pigs distributed over the four stations were: food conversion 3,404 Scand. feed units $/ \mathrm{kg}$ live weight gain, daily gain $0,555 \mathrm{~kg} /$ day, backfat thickness $2,91 \mathrm{~cm}$, area of Musc. long. dorsi $30,6 \mathrm{~cm}^{2}$ and percentage of cutlets $17,20 \%$.

These progeny records are inferior to the results of the 39 boars at Wageningen and the full sibs of these boars at Lochem (see TABLE 2), aspecially with regard to food conversion and daily gain. These discrepancies are very likely due to station effects, sex differences and the fact that the dams of the progeny were mostly unregistered sows from farms with ordinary conditions.

Comparison of the boars' own performance or that of their full sibs with the records of the progeny of the boars is only useful provided the deviations from the respective population means are taken into account. This is shown in TABLE 5. A positive deviation is favourable in the case of the selection index, daily gain, area of Musc. long. dorsi and percentage of cutlets. With respect to food conversion and backfat thickness a negative deviation is favourable, since a low food conversion and thin backfat are desirable.

TABLE 5. Comparison of the boars' own performance or that of their full sibs with the records of the progeny of the boars

\begin{tabular}{|c|c|c|c|c|c|c|c|c|c|c|}
\hline \multirow[t]{3}{*}{ Boar } & \multicolumn{2}{|c|}{ Food conversion } & \multicolumn{2}{|c|}{ Daily gain } & \multicolumn{2}{|c|}{ Backfat thickness } & \multirow{2}{*}{\multicolumn{2}{|c|}{$\begin{array}{c}\text { Area Musc. } \\
\text { long. dorsi }\end{array}$}} & \multirow{2}{*}{\multicolumn{2}{|c|}{$\begin{array}{c}\text { Selection } \\
\text { index I }\end{array}$}} \\
\hline & \multirow{2}{*}{ boar } & \multirow[t]{2}{*}{ progeny } & \multirow[t]{2}{*}{ boar } & \multirow{2}{*}{ progeny } & \multirow{2}{*}{ boar } & \multirow{2}{*}{ progeny } & & & & \\
\hline & & & & & & & boar & progeny & boar & progeny \\
\hline 1 & $-0,361$ & $-0,102$ & $+0,057$ & $+0,007$ & $-0,36$ & $-0,27$ & $+4,4$ & $+0,9$ & +992 & +408 \\
\hline 2 & $+0,348$ & $+0,081$ & $-0,034$ & $-0,008$ & $+0,17$ & $+0,03$ & $-3,3$ & $-0,2$ & -730 & -150 \\
\hline 3 & $+0,607$ & $+0,127$ & $-0,082$ & $-0,026$ & $-0,06$ & $-0,06$ & $-3,1$ & $-2,3$ & -929 & -217 \\
\hline 4 & $+0,440$ & $-0,093$ & $-0,061$ & $+0,008$ & $+0,40$ & $+0,15$ & $+1,8$ & $-0,1$ & -948 & -3 \\
\hline
\end{tabular}

Group II. Boarsselected on the basis of themerits of theirfullsibs

\begin{tabular}{|c|c|c|c|c|c|c|c|c|c|c|}
\hline \multirow[t]{3}{*}{ Boar } & \multicolumn{2}{|c|}{ Food conversion } & \multicolumn{2}{|c|}{ Daily gain } & \multicolumn{2}{|c|}{ Backfat thickness } & \multicolumn{2}{|c|}{$\%$ of cutlets } & \multirow{2}{*}{\multicolumn{2}{|c|}{$\begin{array}{l}\text { Selection } \\
\text { index II }\end{array}$}} \\
\hline & \multirow{2}{*}{ sibs } & \multirow{2}{*}{ progeny } & \multirow{2}{*}{ sibs } & \multirow{2}{*}{ progeny } & \multirow{2}{*}{ sibs } & \multirow{2}{*}{ progeny } & \multirow{2}{*}{ sibs } & \multirow{2}{*}{ progeny } & & \\
\hline & & & & & & & & & sibs & progeny \\
\hline 5 & $-0,207$ & $+0,006$ & $+0,024$ & $+0,009$ & $-0,13$ & 0 & $+0,35$ & $+0,35$ & +433 & +24 \\
\hline 6 & $-0,162$ & $-0,102$ & $+0,022$ & $+0,011$ & $-0,13$ & $+0,01$ & $-0,03$ & $-0,05$ & +352 & +131 \\
\hline 7 & $+0,081$ & $-0,024$ & $-0,016$ & $+0,003$ & $+0,30$ & $+0,05$ & $+0,27$ & $-0,08$ & -377 & -11 \\
\hline 8 & $+0,191$ & $+0,119$ & $-0,031$ & $-0,006$ & $+0,12$ & $+0,10$ & $-0,90$ & $+0,12$ & -446 & -244 \\
\hline
\end{tabular}

Group I of TABLE 5 includes the four boars selected on the basis of their own merits. For each character and for the index, the boar's own performance is first given, and then the performance of its progeny. The boar's own performance is expressed as a deviation from the mean of the 39 boars tested. As mentioned earlier, the performance of each boar's progeny is expressed as a deviation from the mean of the eight progeny groups.

Group II includes the four boars selected on the merits of their full sibs. The performance of the boar's full sibs and that of its progeny are shown in succession for each character as well as for the index. The performance of the full sibs of a boar is expressed as a deviation from the average of all 39 full-sib groups tested. Inspection of TABLE 5 shows that in general superior or inferior qualities of both boars and full sibs reappear in the progeny of the boars. This is most striking in 
the case of the selection index. It is also obvious that the breeding value of a boar cannot be predicted with entire accuracy. Boars 4 and 7 had better progeny and boar 5 poorer progeny than was expected.

\section{Comparison of the two selection methods}

In order to compare the merits of the two selection methods the average selection differential $S$ and the average selection response $R$ of the index and the separate characters are presented in TABLE 6.

$S_{i}$ is the selection differential applied with individual selection; it shows the mean deviation of the four boars - chosen on the basis of their own performance - from the mean performance of all 39 boars tested. So $S_{i}$ is the average of the four boar deviations of group I, TABLE 5, the sign of the deviations being disregarded.

$\mathbf{R}_{\mathrm{i}}$ is the selection response with individual selection; it shows the mean deviation of the progeny in the same direction as their sires. Hence $R_{i}$ is the mean of the four progeny-group deviations of group I, TABLE 5. Progeny deviations having the same sign as their corresponding boar deviations are considered to be positive. And progeny deviations having the opposite sign of their corresponding boar deviations are considered to be negative.

$S_{s}$ and $R_{s}$ are the selection differential and selection response respectively with sib selection. They are calculated in a similar manner from the records of group II, TABLE 5 .

The selection response is an indication of the success of selection, and TABLE 6 shows that the response $\mathbf{R}_{i}$ with individual selection is greater than the response $\mathbf{R}_{s}$ with sib selection. This is true of both the separate characters and the index.

TABLE 6. Selection differential and selection response with both selection methods

\begin{tabular}{|c|c|c|c|c|}
\hline \multirow[t]{3}{*}{ Character } & \multicolumn{4}{|c|}{ Selection method } \\
\hline & \multicolumn{2}{|c|}{ individual selection } & \multicolumn{2}{|c|}{ sib selection } \\
\hline & $\begin{array}{c}\text { selection } \\
\text { differential } S_{i}\end{array}$ & $\begin{array}{c}\text { selection } \\
\text { response } R_{i}\end{array}$ & $\begin{array}{c}\text { selection } \\
\text { differential } S_{s}\end{array}$ & $\begin{array}{c}\text { selection } \\
\text { response } R_{s}\end{array}$ \\
\hline$\ldots \ldots \ldots$ & 900 & 194,5 & 402 & 102,5 \\
\hline Food conversion $\ldots \ldots \ldots$ & 0,439 & 0,054 & $\mathbf{0 , 1 6 0}$ & 0,048 \\
\hline Daily gain . .... & 0,059 & 0,008 & 0,023 & 0,006 \\
\hline Backfat thickness ... & 0,25 & 0,13 & 0,17 & 0,04 \\
\hline Area of Musc. long. dorsi . . & 3,2 & 0,8 & - & 一 \\
\hline$\%$ of cutlets $\ldots \ldots \ldots \ldots$ & - & - & 0,39 & 0,05 \\
\hline
\end{tabular}

In the following we confine ourselves to the selection index. The t-test was used for testing wether the responses $R_{i}$ and $R_{s}$ differ significantly from zero. This is shown below.

$\begin{array}{lcccccc} & \text { Response } & \begin{array}{c}\text { Standard } \\ \text { deviation }\end{array} & \begin{array}{c}\text { Degrees of } \\ \text { freedom }\end{array} & \text { t-value } & \text { P (one-sided) } \\ \text { Individual selection } & \mathbf{R}_{\mathbf{i}}= & 194,5 & 443 & 85 & 4,07 & \mathbf{P}<0,001 \\ \text { Sib selection } & \mathbf{R}_{\mathbf{s}}= & 102,5 & 402 & 82 & 2,33 & 0,01<\mathbf{P}<0,05\end{array}$

The response with individual selection is significant at the $0,1 \%$ level and the response with sib selection at the $5 \%$ level. The single-tail test is used here because the theoretical expectation is that selection will have a positive effect. 
Individual selection is $\frac{194,5}{102,5}=1,9$ times better than sib selection, but the difference of 92 index-units is found to be non-significant: $t_{167}=1,41 ; 0,05<P<0,10$. The single-tail t-test is again used, because, as will be explained below, from a theoretical point of view individual selection is more efficient than sib selection.

It also follows from TABLE 6 that the selection differential $\left(S_{i}\right)$ applied with individual selection is much bigger than with sib selection $\left(\mathrm{S}_{\mathrm{s}}\right)$. This is the result of the bigger (although not significantly bigger) response with individual selection. The selection differential $S$ is the product of the selection intensity $i$ and the phenotypic standard deviation $\sigma_{\mathrm{P}}$, hence $\mathrm{S}=\mathrm{i} \sigma_{\mathrm{P}}$ (see, for instance, FALConer, 1960).

The selection intensity directly depends on the percentage of tested animals selected for breeding. In our experiment the percentage of boars selected - and consequently the selection intensity - is the same in both selection methods, so that the selection differential $S$ is directly proportional to the phenotypic standard deviation $\sigma_{\mathrm{P}}$. Since $\sigma_{\mathrm{P}}$ of the boars is bigger than $\sigma_{\mathrm{P}}$ of the full-sib averages (see also TABLE 2), it is obvious that the selection differential must be bigger with individual selection.

\section{Realised heritability of the selection index}

The response of selection can be predicted from the equation (see FALCoNer, 1960):

$$
\mathbf{R}=\frac{1}{2} \mathbf{S h}^{2}=\frac{1}{2} \mathrm{i} \sigma_{\mathrm{P}} \mathbf{h}^{2}
$$

Thus the response is half the product of the selection differential $\mathbf{S}$ and the heritability $h^{2}$. The factor $\frac{1}{2}$ is due to the fact that in our experiment selection was only carried out among the boars and not among the sows. Each boar was mated with a random, unselected, group of females. The actual responses $\left(\mathbf{R}_{\mathbf{i}}\right.$ and $\left.\mathbf{R}_{\mathrm{s}}\right)$ and the selection differentials applied $\left(S_{i}\right.$ and $\left.S_{s}\right)$ are known and substitution of these values in equation (1) gives the realised heritability of the selection index. This is done for individual selection and sib selection separately and the results are shown below:

realised heritability

individual selection

$$
\begin{aligned}
& \mathbf{h}_{\mathrm{i}}^{2}=0,43 \\
& \mathbf{h}_{\mathrm{s}}^{2}=0,51
\end{aligned}
$$

Heritability is lower with individual selection than with sib selection, but $h_{i}^{2}$ refers to individual values and $h_{s}^{2}$ to full-sib averages. The heritability of sib averages can be expressed in terms of the heritability of individual values by means of the following equation (see FALCONER, 1960):

$$
\mathbf{h}_{\mathrm{s}}^{2}=\frac{0,5 \mathrm{n}}{1+(\mathbf{n}-1) \mathrm{t}} \mathrm{h}_{\mathbf{i}}^{2}
$$

in which $\mathrm{n}=$ number of full sibs $(=4)$

$\mathrm{t}=$ phenotypic correlation between full sibs $=0,5 \mathrm{~h}^{2}+\mathrm{c}^{2}$

The term $\mathrm{c}^{2}$ denotes the fraction of the total variance of a character due to environmental correlation between family members. There may be many sources of environmental correlation between full sibs in pigs, for instance their common prenatal uterine 
environment and the common environment during suckling. The environmental correlation between full sibs is probably fairly low for the characters combined in our selection index, since the full sibs were individually housed and fed at the progenytesting station.

Substituting $\mathrm{n}=4, \mathrm{~h}_{\mathrm{s}}^{2}=0,51$ (found in this experiment) and $\mathrm{c}^{2}=0$ (assuming no environmental correlation between full sibs) in equation (2) yields $h_{i}^{2}=0,41$, and this value shows very good agreement with the $h_{i}^{2}=0,43$ actually found.

Although the heritability of sib averages is higher than that of individual values, it is still too low to compensate the smaller standard deviation of the sib averages. This results in a lower selection response with sib selection than with individual selection.

A realised heritability of about 0,40 is fairly high, but still lower than the heritabilities chosen for the separate characters to combine the selection index. These all varied from 0,5 to 0,6 , thus confirming our suspicion that these heritabilities were too high.

\section{Theoretical effectiveness of the two selection methods}

If the selection intensity is assumed to be the same in both methods, the response with sib selection $R_{s}$ can be expressed in terms of the response with individual selection $R_{i}$ by means of the following equation (FALCONER, 1960):

$$
\mathbf{R}_{\mathrm{s}}=\frac{0,5 \mathrm{n}}{\sqrt{\mathrm{n}\{1+(\mathrm{n}-1) \mathrm{t}\}}} \mathbf{R}_{\mathrm{i}}
$$

in which $\mathrm{n}$ and $\mathrm{t}\left(=0,5 \mathrm{~h}^{2}+\mathrm{c}^{2}\right)$ are the same as in equation (2).

Substituting $n=4$ (the number of full sibs per test group in our experiment), $h^{2}=$ 0,40 (approximately found in our experiment), and $c^{2}=0$ (assuming no environmental correlation between full sibs) gives $R_{\mathrm{s}}=0,79 \mathbf{R}_{\mathrm{i}}$. And if we take $\mathrm{c}^{2}=0,1$ (a not unrealistic value) instead of $c^{2}=0$, we find $R_{s}=0,73 R_{i}$.

Hence from a theoretical point of view individual selection is about 1,33 times better than sib selection with the same conditions as in our experiment.

\section{Discussion}

In this experiment the response with individual selection was 1,9 times better than with sib selection, although not significantly so. Theoretical consideration also shows that individual selection is superior to sib selection.

An additional advantage of individual selection is that it takes less pens. With individual selection each boar tested requires one pen, whereas with sib selection each boar tested requires four pens for his four full sibs. Hence with the same capacity four times as many boars can be tested with individual selection; this advantage will be reduced, however, as it will often be possible to use more than one full brother of the four tested litter mates for breeding. But the average number of full brothers kept for breeding will seldom exceed two because two barrows are needed already for testing. Even then individual selection permits of a more intense selection and this results in a better response.

The experiment described was limited, so that the results should be interpreted with 
some caution. However, other investigations support our opinion that the performance test can be a useful tool for the genetic improvement of the pig population. KRIDER et al. (1946) and BAIRD et al. (1952) applied individual selection for high and low daily gain to several generations of Hampshire pigs and obtained good results. Effective individual selection for five generations in Durocs to test food efficiency has been reported by Dickerson and Grimes (1947). At Beltsville, Hetzer et al. $(1956,1963)$ successfully applied individual selection for backfat thickness in Durocs and Yorkshires for several generations. Backfat thickness was measured by probing the live animals at about $80 \mathrm{~kg}$ live weight. Fewson et al. (1962) also obtained good results with selection for backfat thickness in the Improved German Landrace. They used the lean-meter to determine the backfat thickness of the live animal.

A disadvantage of the performance test is that no information is supplied on characters as meat quality (colour, texture, juiciness and taste). It is very likely that with a further rise of the standard of living there will be an increased demand for better quality meat, so that it will be worthwhile to select for this character, provided the commercial pig farmers are paid for better meat quality.

If breeders also want to improve characters that can only be measured after slaughter, e.g. meat quality, they can choose between two selection methods, viz. pure sib testing and a combination of performance testing and sib testing. Theoretical examination has shown that the latter is to be preferred to sib testing alone because the characters that are measurable on the live animals (food conversion, daily gain, backfat thickness) are now much more important than the characters that can only be measured after slaughter (MINKEMA, 1963).

Many combinations of performance testing and sib testing can be made, but in our opinion the best way is to test two boars and two gilts per litter. The boars can be judged from their own records as well as the records of their slaughtered fullsisters.

The final conclusion is that the performance test, applied on its own or in combination with the sib test, can provide an important contribution to the genetic improvement of pigs.

BAIRD, D. M.,

A. V. Nalbandov and H. W. NoRTON

Dickerson, G. E., and J. C. Grimes

FEWSON, D., M. FENDER und W. KIRSCH

Fredeen, H. T., and P. JONSSON

HeTzer, H. O., W. R. HARVEY and W. H. Peters

HETZER, H. O., and

J. H. ZeLLER

\section{RE F E R E N C ES}

1952 Some physiological causes of genetically different rates of growth in swine. J. Anim. Sci. 11, 292.

1947 Effectiveness of selection for efficiency of gain in Duroc swine. J. Anim. Sci. 6, 265.

1962 Prüfungsanstalten als Hilfsmittel für die Selektion in der Schweinezucht. 2. Selektionsversuch zur Prüfung der Effektivität der Eigenleistungsprüfung von Ebern. Zeitschr. f. Tierz. und Zücht.biol. 77, 265.

1957 Genic variance and covariance in Danish landrace swine as evaluated under a system of individual feeding of progeny test groups. Zeitschr. f. Tierz. und Zücht.biol. 70, 348.

1963 Selection for high and low fatness in Duroc and Yorkshire swine. Genetics Today, Proc. XIth Intern. Congr. Genetics, The Hague, 1963. Vol. I, p. 268.

1956 Selection for high and low fatness in Duroc and Yorkshire swine. J. Anim. Sci. 15, 1215. 
JoNSSON, P.

\author{
banks, W. E. Carroll
}

KRIDER, J. L., B. W. FaIR- 1946 and E. ROBERTS

MINKEMA, D.

-, en D. KROESKE
1959 Investigations on group feeding versus individual feeding and on the interaction between genotype and environment in pigs. Acta Agric. Scand. 9, 204.

1963 Danish pig-progeny testing results. Zeitschr. Tierz. und Zücht. biol. 78, 205.

Effectiveness of selecting for rapid and for slow growth rate in Hampshire swine. J. Anim. Sci. 5, 3.

1963 Selektiemethoden bij varkens. Genen en Phaenen. 8, 13.

1963 Afstammelingenonderzoek van beren. I.V.O. Rapport No. B 42. 